\title{
JENIS TUMBUHAN PEWARNA ALAM YANG DIMANFAATKAN OLEH MASYARAKAT PENENUN DESA BATU LINTANG KECAMATAN EMBALOH HULU KABUPATEN KAPUAS HULU
}

(Types of Natural Dyes Used by Weavers Community from Batu Lintang Village, Embaloh Hulu District, Kapuas Hulu Regency)

\author{
Dayang Eva Kartini, Lolyta Sisillia \\ Fakultas Kehutanan Universitas Tanjungpura, Jalan Imam Bonjol Pontianak, 78124 \\ Email : eva.kartini123@gmail.com
}

\begin{abstract}
Forest has many resources which used by the community with their local wisdom. The weaver community from Dayak Iban tribes in Batu Lintang village, Embaloh Hulu district, Kapuas Hulu regency, West Kalimantan province used traditional natural dyes for their product. The natural dyes achieved from the forest near their village. This study aimed to exploration the types of natural dyes uses by the weaver community in Batu Lintang village, Embaloh Hulu district, Kapuas Hulu regency, West Kalimantan province. Methodology of research used indepth interview to the weaver and exploration the plants in the forest. Result of the research showed that seven species of natural dye used daily in the village. The name of the plants were Tarenna fragrans (Rubiaceae), Psychotria malayan (Rubiaceae), Morinda citrifolia (Rubiaceae), Peristrophe bivalvis (Acanthaceae), Clerodendrum laevifolium (Lamiaceae), Senna siamea (Fabaceae), and Eusideroxylon zwageri (Lauraceae). They used the leaf, root and stem of the plant. The color from Tarenna fragrans and Morinda citrifolia was brown, Psychotria malayan was red brown, Peristrophe bivalvis and Eusideroxylon zwageri was red, Clerodendrum laevifolium and Senna siamea was green and black. The community of Batu Lintang village still maintained the tree in the forest. These traditional natural dyes need preservations and technology to get the better result for their products.
\end{abstract}

Keywords: Batu Lintang village, Dayak Iban, Kapuas Hulu, natural dyes, woven fabrics

\section{PENDAHULUAN}

Indonesia merupakan negara kepulauan yang sangat luas, yang mempunyai kurang lebih 35.000 pulau yang besar dan kecil dan keanekaragaman jenis flora dan fauna yang sangat tinggi. Di Indonesia dapat diperkirakan terdapat 100 sampai 150 famili tumbuh-tumbuhan dan dari jumlah tersebut sebagian besarnya memiliki potensi untuk dimanfaatkan sebagai tanaman buah-buahan, tanaman industri, tanaman rempah-rempah, tanaman pewarna dan tanaman obatobatan (Nasution, 1992). Berkembangnya ilmu pengetahuan dan berubahnya gaya hidup manusia yang cepat karena intervensi global mengakibatkan masyarakat tradisional mulai perlahanlahan meninggalkan tradisinya terutama dalam pemanfaatan tumbuhan. Manusia sejak dahulu menggunakan tumbuhan dan berinteraksi dengan alam sekitarnya. Dalam perkembangan kehidupan manusia, tumbuhan telah memainkan peranan yang sangat penting dalam kehidupan manusia karena merupakan sumber pangan, papan, sandang, obat, kerajinan, kegiatan sosial dan sebagainya. Adanya interaksi antara masyarakat lokal dengan lingkungan alamnya, terutama mengenai penggunaan 
tumbuhan yang dikenal dengan etnobotani (Martin,1998a). Potensi sumber daya alam di hutan adat, khususnya tumbuhan tidak lepas dari kepentingan masyarakat sekitar kawasan untuk berbagai kegunaan (Anonim 1999). Salah satu masyarakat yang masih mempertahankan kearifan lokal seperti adat dan tradisi dalam penggunaan sumber daya alam khususnya tumbuhan yang dimanfaatkan sebagai pewarna alam adalah masyarakat Dayak Iban di Desa Batu Lintang Kecamatan Embaloh Hulu Kabupaten Kapuas Hulu. Beberapa jenis tumbuhan yang dimanfaatkan masyarakat penenun yang dikembangkan dan dijadikan tradisi oleh masyarakat. Oleh karena itu untuk mengetahui jenis tumbuhan pewarna alami yang dimanfaatkan oleh masyarakat maka diperlukan penelitian kajian etnobotani tumbuhan pewarna alami sehingga dapat dimanfaatkan untuk kepentingan lebih lanjut.

\section{METODE PENELITIAN}

Penelitian dilaksanakan di kawasan Desa Batu Lintang Kecamatan Embaloh Hulu Kabupaten Kapuas Hulu Provinsi Kalimantan Barat dengan waktu penelitian selama 3 minggu di lapangan pada bulan Mei 2017. Adapun objek dari penelitian ini yaitu tanaman yang dimanfaatkan oleh masyarakat penenun dan mendeskripsikan ciri-ciri morfologi tanaman pewarna alam oleh masyarakat Desa Batu Lintang. Alat dan bahan yang digunakan berupa daftar pertanyaan atau kuisioner untuk reponden terpilih, buku identifikasi tumbuhan, kamera untuk mendokumentasi, benang putih tenun untuk keperluan dokumentasi warna tanaman, kain putih polos untuk keperluan dokumentasi jenis tanaman.
Metode penelitian dilakukan dengan wawancara mendalam (in-depth interview) dengan masyarakat penenun di Desa Batu Lintang. Selanjutnya dilakukan eksplorasi tanaman yang dijadikan sebagai bahan pewarna di hutan yang terdapat di sekitar Desa Batu Lintang. Penentuan lokasi pengambilan tanaman pewarna secara eksploratif yaitu menjelajahi setiap sudut lokasi yang dapat mewakili tipe-tipe ekosistem atau tipe-tipe vegetasi di kawasan yang diteliti (Ruqayah, 2004). Data hasil yang diperoleh disajikan dalam bentuk tabel yang memuat jenis tumbuhan (dalam nama Indonesia), nama ilmiah, famili /suku dan bagian / organ tumbuhan yang digunakan.

\section{HASIL DAN PEMBAHASAN}

Tumbuhan yang dimanfaatkan sebagai tanaman pewarna alam oleh masyarakat penenun di Desa Batu Lintang Kecamatan Embaloh Hulu Kabupaten Kapuas Hulu sebanyak tujuh jenis tumbuhan. Penggunaan tumbuhan dan pengetahuan penggunaan pewarna diperoleh secara turun temurun. Pohon yang digunakan dipelihara dengan baik sehingga pemanfaatannya dapat dilakukan secara berkelanjutan. Martin (1998b) menyatakan masyarakat akan melestarikan tumbuhan yang digunakan untuk upacara adat serta untuk kebutuhan hidupnya. Bagian yang digunakan adalah daun, akar dan batang. Hal ini sesuai dengan hasil penelitian Sutara (2009) yang menyatakan bagian yang banyak digunakan sebagai pewarna alami di perusahan tenun di Gianyar adalah daun dan batang. Jenisjenis tumbuhan yang digunakan sebagai pewarna alam adalah Tarenna fragrans (Rubiaceae) berwarna coklat, Psychotria 
malayan (Rubiaceae) berwarna merah kecoklatan, Morinda citrifolia (Rubiaceae) berwarna coklat, Peristrophe bivalvis (Acanthaceae) berwarna merah tua, Clerodendrum laevifolium (Lamiaceae) berwarna hijau tua/ hitam, Senna siamea (Fabaceae) berwarna hijau tua/ hitam, dan Eusideroxylon zwageri (Lauraceae) berwarna merah. Beberapa jenis tanaman yang digunakan di Desa Batu Lintang sama dengan yang digunakan oleh masyarakat Dayak Iban di Desa Mensiau Kabupaten Kapuas Hulu (Santa dkk 2015). Jenis tumbuhan penghasil warna disajikan pada Tabel 1 .

Tabel 1. Jenis, bagian yang digunakan, warna yang dihasilkan tanaman pewarna alam. (the species, parts used, color produced from plants natural dye)

\begin{tabular}{cllll}
\hline No & \multicolumn{1}{c}{ Nama Lokal } & \multicolumn{1}{c}{ Nama Latin } & \multicolumn{1}{c}{$\begin{array}{c}\text { Bagian yang } \\
\text { digunakan }\end{array}$} & \multicolumn{1}{c}{$\begin{array}{c}\text { Warna yang } \\
\text { dihasilkan }\end{array}$} \\
\hline 1 & Engkrebai Hutan Betina & Tarenna fragrans & daun tua & coklat \\
2 & Engkrebai Hutan Jantan & Psychotria malayan & daun tua & merah kecoklatan \\
3 & Engkrebai Laut & Peristrophe bivalvis & daun tua & merah tua \\
4 & Mengkudu & Morinda citrifolial & akar & coklat \\
5 & Rengat Kikat & Clerodendrum laevifolium $b$ & daun tua & hijau tua/ hitam \\
6 & Rengat Padi & Senna siamea & daun \& batang & hijau tua/ hitam \\
7 & Kayu Ulin & Eusideroxylon zwageri & batang kayu & merah \\
\hline
\end{tabular}

Adapun ciri morfologi tanaman pewarna yang dimanfaatkan sebagai berikut :

\section{Tarenna Fragrans}

\section{Batang}

Ciri-ciri morfologi: termasuk dalam habitus pohon, batang utama tumbuh tegak, kulit batang kasar terdapat bercakbercak besar bewarna coklat dan putih, batang keras, tinggi mampu mencapai 12 m dengan diameter $15 \mathrm{~cm}$ dbh. Bentuk batang lurus ke atas mempunyai banyak cabang (Gambar 1).

\section{Daun}

Bentuk daun lonjong berwarna hijau tua dengan panjang daun mencapai $15 \mathrm{~cm}$, ujung daun runcing, permukaan daun halus, tulang daun tersier, memiliki buah/biji bulat kecil (Gambar 2).

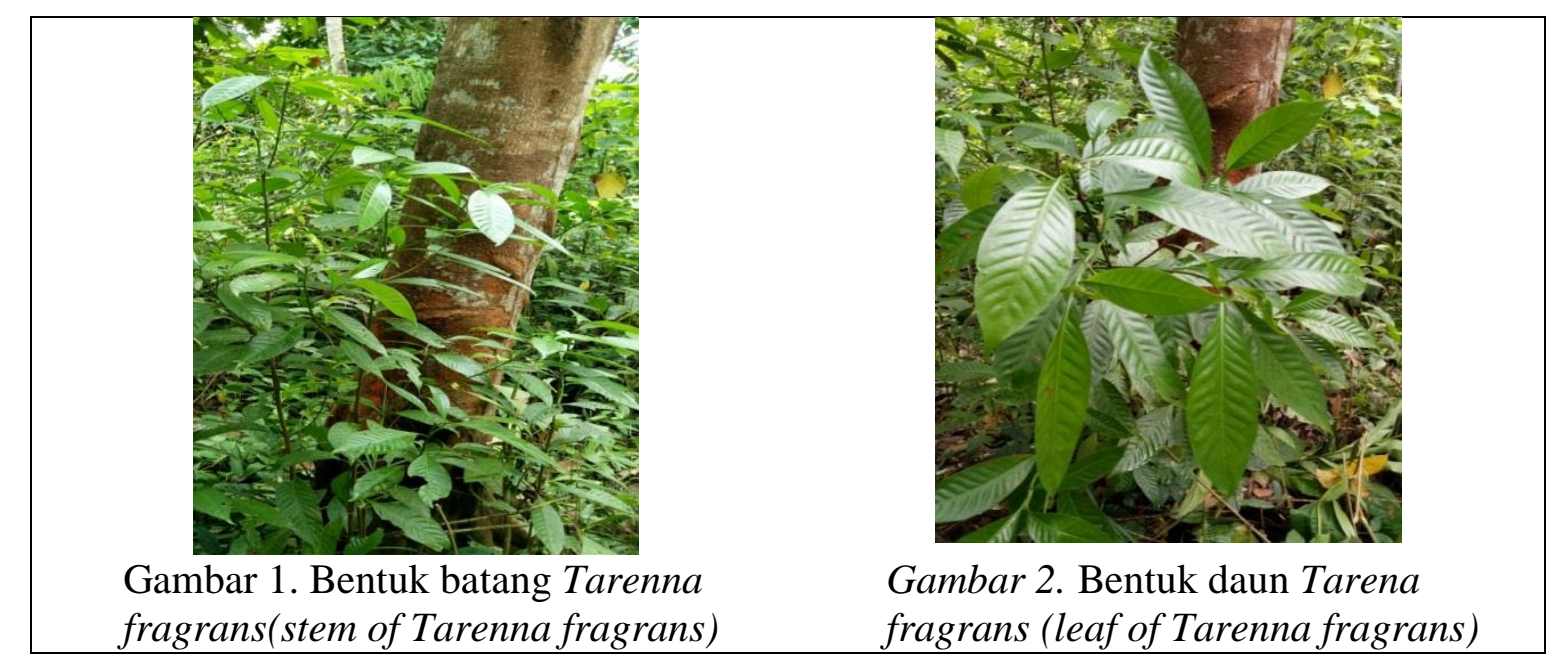




\section{Psychotria malayan}

\section{Batang}

Tinggi mampu mencapai 6-8 m, kulit batang kasar berwarna coklat muda, terdapat bercak putih kecil-kecil, batang menjulang lurus keatas, terdapat banyak percabangan (Gambar 3).

\section{Daun}

Permukaan daun halus berwarna hijau muda, bentuk daun runcing dengan bentuk tulang daun menyirip, daun mengkilap, panjang daun mencapai 12 cm (Gambar 4).

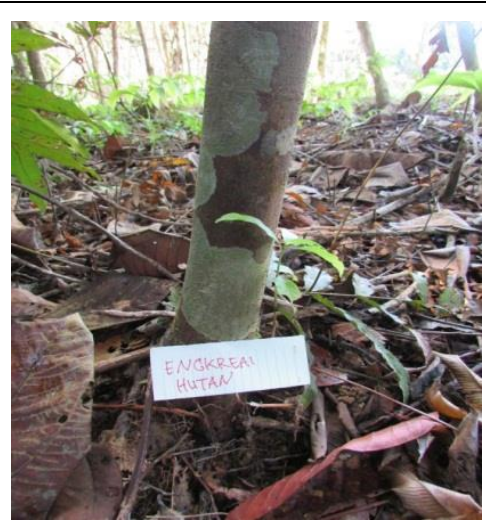

Gambar 3. Bentuk batang Psychotria malayan (stem of Psychotria malayan)

3. Senna siamea

\section{Batang}

Kulit batang kasar bewarna coklat berlubang, kulit batang seperti merekah, merupakan jenis pohon dengan tinggi mencapai 3-8 meter, memiliki banyak percabangan (Gambar 5).

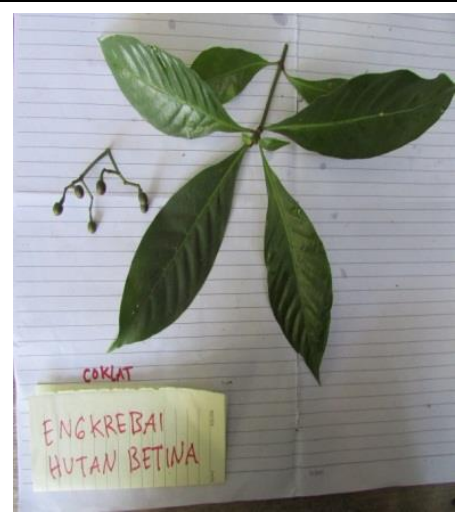

Gambar 4. Daun Psychotria malayan (leaf of Psychotria malayan )

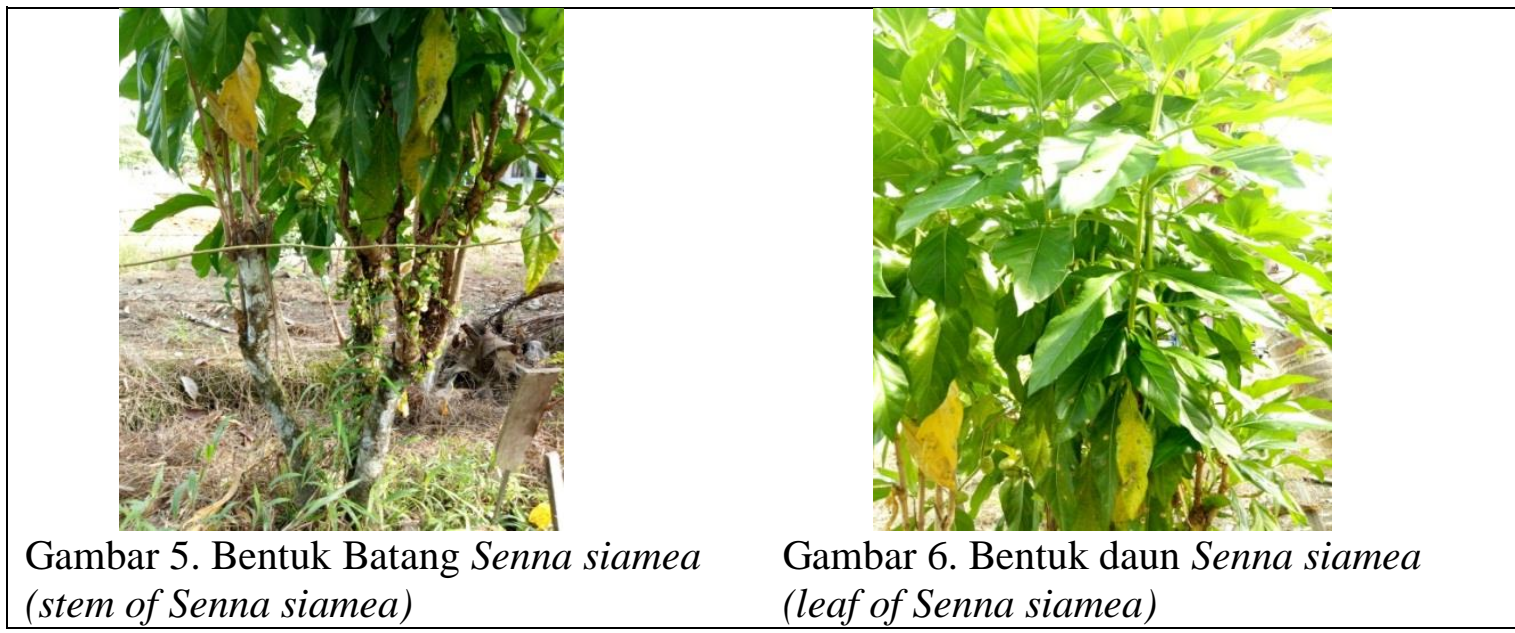




\section{Morinda citrifolia L}

\section{Batang}

Termasuk dalam jenis pohon yang mencapai 3-8 m, batang utama tumbuh tegap, memiliki banyak cabang, kulit batang coklat dan terdapat bercak putih besar, kulit batang kasar (Gambar 7).

\section{Daun}

Helaian daun berbentuk bulat telur, ujung daun runcing, permukaan daun berwarna hijau berkilau, panjang daun mencapai $25 \mathrm{~cm}$, bunga berbau harum dan buah berbentuk bongkol (Gambar 8).

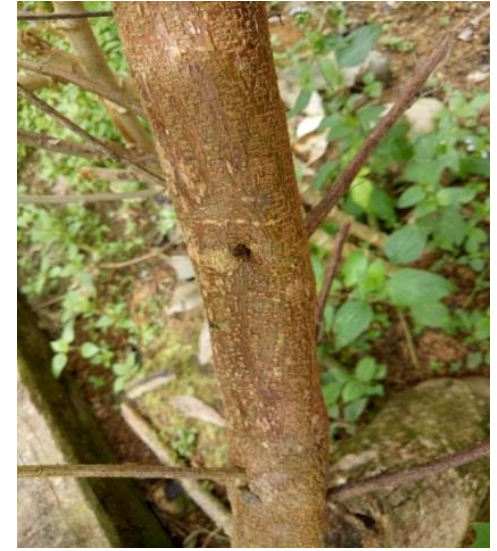

Gambar 7. Bentuk batang Morinda citrifolia L (stem of Morinda citrifolia L)

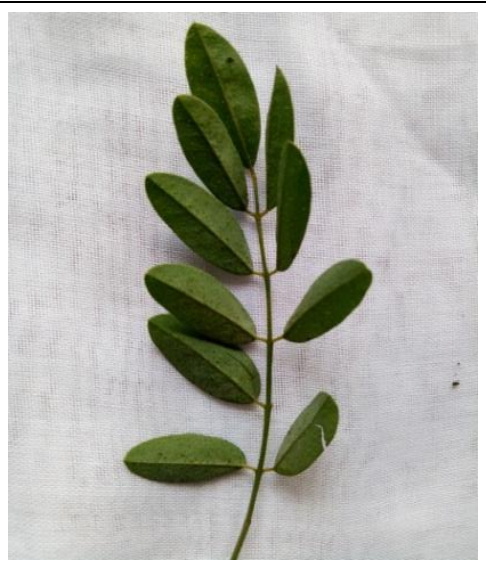

Gambar 8. Bentuk daun Morinda citrifolia L (leaf of Morinda citrifolia $L$

\section{Eusideroxylon zwageri}

\section{Batang}

Termasuk dalam jenis pohon dengan tinggi pohon mencapai 8-20 m diameter mencapai $120 \mathrm{~cm}$. Batang utama tumbuh tegak, batangnya keras dan biasa memiliki lobang di bagian kulit kayu (Gambar 9).

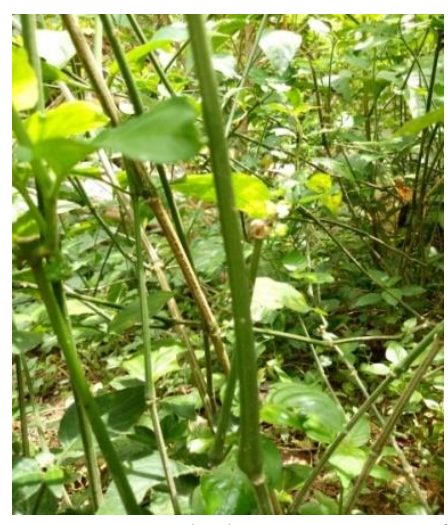

Gambar 9. Bentuk batang Eusideroxylon zwageri (stem of Eusideroxylon zwageri)

\section{Daun}

Panjang daun mencapai 14-18 cm dengan lebar sampai 5-11 cm, daun berwarna hijau tua, bentuk daun elip (Gambar 10).

\begin{tabular}{|l} 
zwageri (stem of Eusideroxylon zwageri) \\
zwageri (Leafof Eusideroxylon zwageri)
\end{tabular}


JURNAL TENGKAWANG (2017)

Vol. 7 (2) : 84 - 91

\section{Peristrophe bivalvis}

\section{Batang}

Merupakan jenis perdu, tinggi sampai 2 $\mathrm{m}$, hidup bergerombol, batang hijau berbuku-buku, kulit batang kasar (Gambar 11).

\section{Daun}

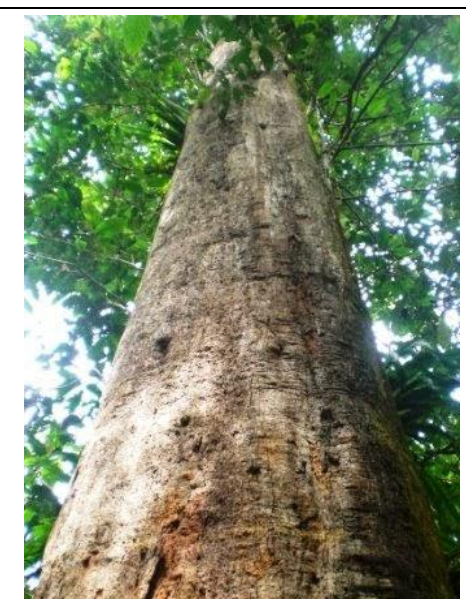

Gambar 11. Bentuk batang Peristrophe bivalvis (stem of Peristrophe bivalvis)

\section{Clerodendrum laevifolium}

\section{Batang}

Merupakan jenis perdu, bergerombol, tinggi mencapai $2 \mathrm{~m}$, batang bewarna hijau tua, kulit batang kasar, memiliki banyak cabang (Gambar 13).

Daun
Panjang daun mencapai $10 \mathrm{~cm}$ dengan lebar daun sampai $6 \mathrm{~cm}$, daun berbentuk bulat telur, ujung daun runcing, permukaan daun seperti berbulu, warna daun hijau muda, tulang daun sekunder, pangkal daun bulat (Gambar 12).

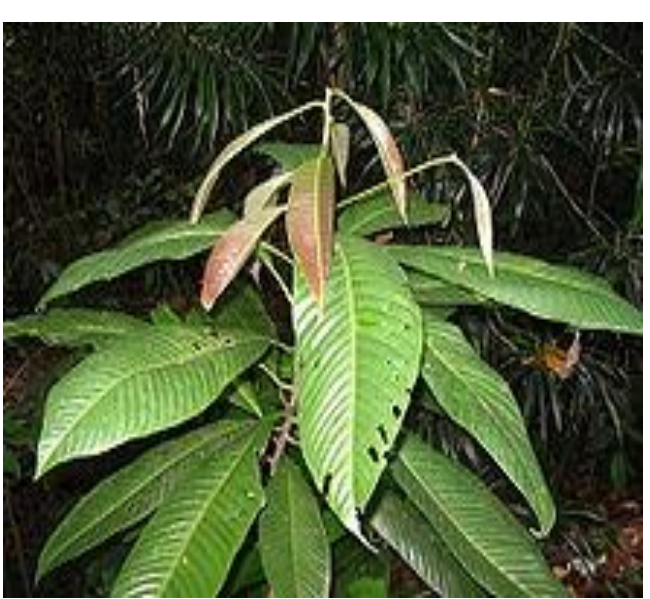

Gambar 12. Bentuk daun Peristrophe bivalvis (leaf of Peristrophe bivalvis)

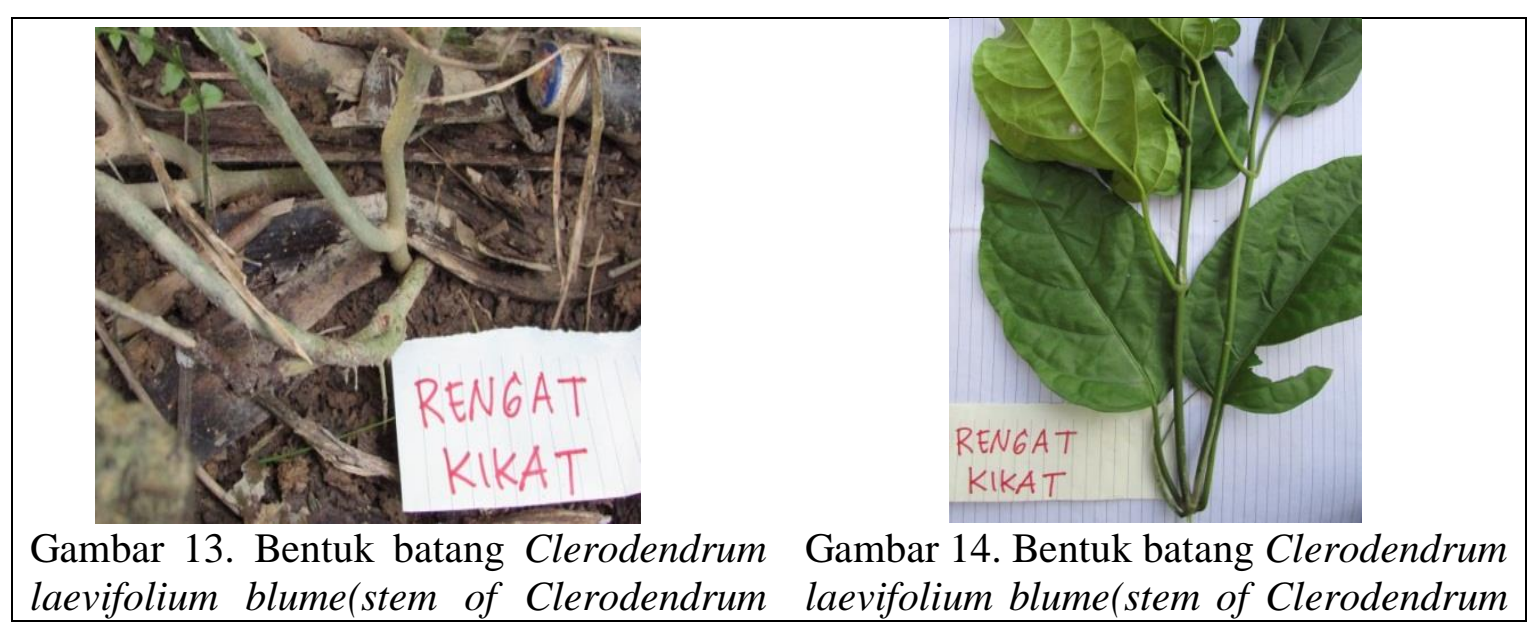


laevifolium blume)

Tanaman yang ditemukan ini berada di pekarangan rumah dan di hutan atau di sekitar hutan adat. Tanaman pewarna mudah untuk ditemukan ditambah lagi batang sisa tanaman dapat dibudidayakan atau ditanam kembali. Tumbuhan pewarna alam ini sangat bermanfaat bagi masyarakat dalam menunjang kegiatan pewarnaan tradisional. Masyarakat sekitar telah memanfaatkan tanaman pewarna dari zaman nenek moyang yang disampaikan secara turun temurun. Masyarakat Desa Batu Lintang Kecamatan Embaloh Hulu Kabupaten Kapuas Hulu menggunakan pewarna alam untuk mewarrnai benang yang ditenun untuk dijadikan baju adat, rok adat, selimut dan syal yang dapat dijual dan dipakai sendiri. Pengolahan tanaman pewarna menggunakan bahanbahan tradisional seperti air dan kapur sirih dengan cara memasak tanaman pewarna hingga mendidih lalu direndam pada benang tenun kemudian dijemur.

\section{Kesimpulan}

\section{PENUTUP}

1. Ditemukan tujuh spesies tanaman yang dikelompokkan dalam lima famili yang digunakan untuk mewarnai benang atau pakaian yaitu Engkrebai Hutan Betina (Tarenna fragrans), Engkrebai Hutan Jantan (Psychotria malayan), Mengkudu (Morinda citrifolia l), Rengat Kikat (Clerodendrum laevifolium blume), Rengat Padi (Senna siamea), Engkrebai Laut (Peristrophe bivalvis), dan Kayu Ulin (Eusideroxylon zwageri).

2. Berdasarkan warna yang dihasilkan Tarenna fragrans dan Morinda citrifolia $l$ menghasilkan warna coklat, Psychotria malayan menghasilkan warna merah kecoklatan, Peristrophe bivalvis laevifolium blume)

menhasilkan warna merah tua, Clerodendrum laevifolium dan Senna siamea menghasilkan warna hijau tua/hitam dan Eusideroxylon zwageri menghasilkan warna merah.

\section{Saran}

1. Diperlukan sosialisasi dan pembinaan secara terpadu mengenai pemanfaatan sumber daya alam dan hayati dari pemerintah supaya masyarakat dapat mengetahui pentingnya pelestarian dan perkembangan daerah.

2. Diperlukan pelestarian dan pembudidayaan tanaman pewarna alam di pekarangan rumah dan disekitar Hutan Adat agar mudah di peroleh.

\section{DAFTAR PUSTAKA}

Anonim, 1999, Bangkitnya warnawarna alam proses ekstraksi dan pudarisasi bahan pewarna alam, Makalah Seminar Bangkitnya Warna-Warna Alam, Departemen Perindustrian dan Perdagangan, Yogyakarta

Martin, GJ. 1998a. Etnobotany, A People And Plants Conservation Manual. Penerjemah Maryati Mohamad Chapman And Hall, London.

Martin GJ. 1998b. Etnobotani: Sebuah Manual Pemeliharaan Manusia Dan Tumbuhan. Mohamed M, Penerjemah. Kota Kinabalu: Natural History Publications (Borneo).

Nasution RE. 1992. Prosiding Seminar dan Loka Karya Nasional Etnobotani. Departemen Pendidikan dan Kebudayaan RILIPI. Perpustakaan Nasional Republik Indonesia 
Ruqayah. 2004. Pedoman Pengumpulan

Data Keanekaragaman Flora.

Bogor Pusat Penelitian Biologi, LIPI.

Santa EK, Mukarlina, Linda R. 2015.

Kajian Etnobotani Tumbuhan Yang Digunakan Sebagai

Pewarna Alami Oleh Suku Dayak Iban Di Desa Mensiau Kabupaten
Kapuas Hulu. Jurnal Protobiont Vol 4 No 1 hal 58-61. Fakultas MIPA : Universitas Tanjungpura. Sutara K.2009. Jenis Tumbuhan Sebagai Pewarna Alam Pada Beberapa Perusahaan Tenun Di Gianyar. Jurnal Bumi Lestari Vol 9 No. 2 Hal 217-223. Jurusan Biologi. Fakultas Mipa.Universitas Udayana. 